\title{
Here or there? Consumer reactions to corporate social responsibility initiatives: Egocentric tendencies and their moderators
}

\author{
Dale W. Russell • Cristel Antonia Russell
}

Published online: 25 July 2009

(C) The Author(s) 2009. This article is published with open access at Springerlink.com

\begin{abstract}
This research examines how consumers react to corporate social responsibility (CSR) programs that vary in geographic focus. Three experiments compare consumers' patronage of a company in response to local and distant CSR initiatives. The extant egocentrism literature suggests that a CSR activity focused locally, and thus, with greater personal relevance, should increase patronage of the company responsible for the CSR activity. Indeed, this egocentric bias, exhibited in the form of increased purchase intentions or actual choices, is found across all three studies. However, these egocentric tendencies are moderated by consumers' superordinate identities. In study 1 , consumers' greater intentions to patronize a company whose CSR activity is domestic vs. foreign are moderated by their sense of global identity. In study 2, consumers' increased choices of a company whose CSR activity is in their home state vs. a distant state are moderated by levels of environmental consciousness. Finally, in study 3 , increased patronage of a company whose CSR activity focuses in consumers' home city vs. a distant city depends on the salience and level of consumers' superordinate group identity.
\end{abstract}

Keywords Egocentrism - Consumer behavior - Corporate social responsibility - Identity

Corporate social responsibility (CSR) efforts are generally instituted to generate goodwill for the company and increase profits. A 2008 survey found that $95 \%$ of corporations recognize the importance of addressing public expectations for businesses to act in a more socially responsible way (Economist). Another survey of 715 top international CEOs found that companies with strong social and

D. W. Russell

School of Public Health / Prevention Research Center, University of California, Berkeley,

50 University Hall, Berkeley, CA 94720, USA

e-mail: DRussell@prev.org

C. A. Russell $(\bowtie)$

Department of Marketing, School of Business, University of Auckland, Auckland 1142, New Zealand

e-mail: c.russell@auckland.ac.nz 
environmental commitments saw profits increase by $16 \%$ and share prices increase by $45 \%$ over a 3 -year period compared to $7 \%$ and $12 \%$, respectively, for those companies without such strong commitments (EIU 2008). Furthermore, 991 multinational corporations reported that enhancing their brand reputation was an important competitive advantage factor when considering the implementation of their CSR activities (EIU 2008). As the public becomes more aware of and sensitive to corporate behavior, both positive and negative, a corporation's CSR reputation will become increasingly important (Berger and Kanetkar 1995; Daviss 1999).

In the end, consumers, through their purchases and consumption of products, are the final judges of corporations' behavior. Consumers' behavior toward a company (e.g., purchasing or boycotting its products) is a function of how they view the company (Klein et al. 2004). As consumers have become more conscious of how their consumption choices impact society, their sensitivity to corporate social behavior has also dramatically increased since the 1980s (Harrison and Freeman 1999). Consumer purchases often transcend the simple value associated with a product and reflect how they perceive the value of the company producing the product in their community, which includes the company's CSR activities. Research has shown that consumers are willing to pay more for products that are produced in a socially responsible manner and that they respond negatively (e.g., by not purchasing their products at all) when companies do not act responsibly (Trudel and Cotte 2008). Consumers who perceive a company as more socially responsible also maintain higher levels of trust towards the company's products (Pivato et al. 2008). Thus, businesses at all levels, but especially at the corporate level, are paying attention to consumers' responses to their CSR strategies (Marin et al. 2009; Podnar and Golob 2007).

The extant literature contains much discussion regarding how corporations could deal with consumers' social and environmental concerns through their CSR activities; however, empirical data are scant. In particular, the academic literature lacks empirical studies regarding how CSR initiatives influence consumers' behavior (Berman et al. 1999; Colonomos and Santiso 2005). This research is in response to calls for greater understanding of how consumers' identities and values affect their behavior and to better understand what considerations are given when consumers flex their economic muscles for social causes (Powell 2006).

\section{Theoretical framework}

The notion that businesses should operate in a neighborly manner and concern themselves with their impact on their fellow citizens is well-accepted (Windsor 2001). But there are many community and geographic levels at which companies can focus their CSR efforts (Economist 2008). This research examines how consumers respond to CSR programs that vary in geographic focus. The studies are guided by the extant literature on egocentrism to compare consumer responses to CSR initiatives that are either local or distant; such geographic foci are often components of corporate strategies to demonstrate community attachment and concern for community welfare (Marin et al. 2009; Handleman and Bello 2004). The studies also assess the role played by consumers' identity as global citizens and 
consumers' environmental consciousness as moderators of their generally egocentric tendencies. In the final study, consumers' subordinate or superordinate group identities are manipulated experimentally to assess the moderating effect of priming different levels of group identity on egocentric tendencies.

\subsection{Egocentric tendencies}

A large body of literature supports the notion that consumers would be more concerned with locally focused CSR initiatives that directly affect their daily lives. Of the many constructs that reflect behaviors promoting self-gratification (e.g., selfishness, idiocentrism, ethnocentrism), the construct of egoism has been deemed the most relevant for assessing relationships between individuals and greater society (Weigel et al. 1999). Many have argued the need to better understand and appreciate the power of egoism, for egocentric decision-making is considered to be "more powerful than any but the most astute psychological analysts and the most rigorous devotees of introspection realize" (Niebuhr 1932, p. 40). Decisions biased by egocentrism override rational decision-making. In fact, philosopher Arthur Schopenhauer deemed egoism "the starting point of all conflict" (Mannion 2003, p. 193), and indeed, consumer behavior relating to economic purchasing power has been deemed a manifestation of personal ravenousness (Dickinson and Hollander 1991).

As with many constructs, egoism has multiple definitions, but it essentially involves behaviors that are self-serving, such as allocating more resources to oneself or one's in-group rather than others (Diekmann 1997). Individuals often are unable to get beyond this egocentrism (Gilovich et al. 2000). According to legal scholar and philosopher Jeremy Bentham, "man, from the constitution of his nature, prefers his own happiness to that of all other sentiment being put together" (Parekh 1974, p. xi). According to this sentiment and the underlying assumptions of classical economics, individuals are thought to generally behave as to maximize their own gain; therefore, every action is motivated by self-interest (Weigel et al. 1999). An important characteristic of egocentric tendencies is their latent nature; they are relatively automatic responses that manifest themselves implicitly in behaviors (Diekmann 1997). This implicit nature of the egocentric bias has two consequences: first, people may not be aware of the bias, and second, more explicit responses, such as judgments of importance or explicit statements of approval, may not be subject to the bias because people are more conscious and aware, and thus, more likely to control their biases. The extant egoism literature thus suggests that, if consumers perceive that a company's CSR activity benefits them directly, they should reciprocate and reward the company through increasing patronage (Morales 2005; Reed et al. 2007). Explicit responses to the company's efforts should not be affected by the egocentric bias.

\subsection{Moderators of egocentrism}

Some factors may moderate or even remove consumers' egocentric biases. For consumers to break the gravitational tug of egoism, they must exhibit what some have termed "empathetic attribution" (Dickinson and Hollander 1991). This concept presents the notion that consumers must be able to recognize the utility of something 
in relation to others or to a greater cause. Therefore, one potential moderator of egocentric tendencies is the degree to which one values an entity greater than an immediately self-serving one. This research focuses on three such superordinate identities: the first two studies measure the degree to which consumers exhibit superordinate identities, an individual's sense of self as a global citizen and an individual's environmental consciousness, and the final study primes an individual's identity as a member of a broad (vs. narrow) community.

It has long been acknowledged that people's moral sense, and thus, their sense of identity, encompasses many layers, such as the family, the neighborhood, the region, the nation, and beyond (Niebuhr 1932). According to social identity theory, people differ in their level of identification with each of these categorizations (Tajfel and Turner 1979). Although most research has focused on smaller groups, such as university or club memberships, some studies have examined individual differences in identification with one's nationality as a predictor of conformity to national cultural norms (Jetten et al. 2002). In general, research on social identity has found that consumers engage in behaviors that are consistent with their identities (Forehand et al. 2002). This research incorporates national, regional identity, as well as some superordinate identities, such as global citizenship and environmental consciousness.

There has been much academic discussion on the changing nature of citizenship in this era of globalization where "traditional citizenship is being challenged and remolded by the important activism associated with this trans-national political and social evolution" (Falk 1994, p. 138). In its basic form, global citizenship reflects the notion that individuals identify with and concern themselves with their impact on their fellow global citizens. The implication of this superordinate identity is that ingroup and out-group distinctions (i.e., us vs. them) give way to a more communal mindset. In a similar manner, environmental consciousness encompasses an overarching societal orientation whereby an individual is concerned with the interplay between human activities, including their own, and the corresponding impact on the natural environment (Kang and James 2007). There is evidence that an individual's level of environmental consciousness influences their purchase behavior (Schlegelmilch and Bohlen 1996) and how they respond to companies' CSR activities (Klein and Dawar 2007). The notion that such superordinate identities are likely to supersede lower-level egocentric tendencies is the premise of this research.

\section{Research objectives}

The goal of this research is to assess consumers' behavioral reactions to CSR activities as a function of the geographic focus of the CSR activity and consumers' sense of identity. In three studies, the focus of a company's CSR activities is manipulated experimentally to reflect either a local or a distant focus. Consumers' reciprocal behavior is then measured in the form of purchases of the company's products (intentions in study 1, actual choice in studies 2 and 3). The research incorporates several dimensions of consumers' identities measured in advance of the experiments (studies 1 and 2) or manipulated at the onset of the experiment (study 3) to assess their moderating impact on consumers' behavior toward the company. 


\subsection{Research context}

The context for the first two studies is a retailer's commitment to sustainable operations. In recent years, CSR efforts and environmental concerns have grown hand in hand, especially as climate change has emerged as a major public concern. Such concern has resulted in many parts of society being scrutinized in an effort to root out and rectify humanity's impact on the environment. The business community is often targeted given its public visibility and the historic impact that commercial activities have had on the planet. Today's consumers are increasingly judging businesses based on their social behaviors, and a company's environmental record is one of the most often cited CSR efforts (Dawkins and Lewis 2003; Klein and Dawar 2007). To ensure that the effects are not specific to the environmental context, the final study adopts a different approach, focusing the CSR activity on assistance for university expenses.

\section{Instrument development}

The studies required several measures of the strength of one's identity: identity as a global citizen, national and regional (state) identity, and identity as a member of a university community. Study 2 also required a measure of environmental consciousness. The measures for each of these constructs were pre-tested in a preliminary phase, using a survey administered to 658 undergraduate students $(54 \%$ males) who were members of a subject pool at a large California public university. In line with previous research on group identification, the measures included three dimensions, namely satisfaction with being a member of a group, the salience of the group membership, and solidarity with a group (Cameron 2004). The same items were used for each geographic level of identity, and they were anchored by strongly disagree/strongly agree. Satisfaction with group membership was measured by "I feel good about being a Californian/an American/a global citizen/a member of a US university," and "I am proud to be a ..." (Ellemers et al. 1999; Luhtanen and Crocker 1992; Sellers et al. 1998). The salience of the group membership was measured by "I often think of the fact that I am a ..." and "Being ... is an important part of my identity" (Jackson 2002). Solidarity with the group was measured by "I feel strong ties to ..." (Cameron 2004) and "I have a strong attachment to ..." (Sellers et al. 1998). All six-item measures performed well in the pre-test, with alphas above 0.87 . The correlations between identity measures were significant but low $\left(r_{\mathrm{CA}}\right.$, US $=0.53$; $r_{\mathrm{US}}$, Global $=0.12, r_{\mathrm{CA}}$, Global $\left.=0.24\right)$, supporting discriminant validity. ${ }^{1}$ Overall, participants reported strong identities as Californians $(M=4.20 ; \mathrm{SD}=0.88)$ and as Americans $(M=4.15 ; \mathrm{SD}=0.83)$, but global citizenship scores $(M=3.55 ; \mathrm{SD}=0.87)$ were more evenly distributed across the scale, with a median of 3.6.

\footnotetext{
${ }^{1}$ Additional discriminant validity tests were conducted (Fornell and Larcker 1981) and are supportive of distinct constructs. In the subsequent studies, correlations between American identity and global citizenship identity and between identity as a Californian and global citizenship identity are not significant ( $r=-0.05$ and 0.14 , respectively, both $\mathrm{ns}$ ).
} 
A three-item measure of environmental consciousness was also pre-tested. The items were based on previous research regarding ecological concern and attitudes toward the environment (Schlegelmilch and Bohlen 1996): "I regularly worry about my impact on the environment," "I think it is important to protect the environment," and "I consider myself an environmentalist." The measure proves reliable, with an alpha of 0.74 , and provided a range of scores $(M=3.28 ; \mathrm{SD}=0.82)$, with a median of 3.33 .

\section{Study 1}

Study 1 adopts a country focus and compares consumer responses to CSR activities conducted in their home country to those conducted in a foreign country.

\subsection{Hypotheses}

Based on the extant egocentrism literature, a CSR activity focused locally, and thus with greater personal impact, is expected to trigger greater reciprocity from consumers in the form of increased future patronage of the company responsible for the CSR activity. However, a consumer's sense of identity as a global citizen is expected to moderate this relationship such that the greater reciprocity triggered by a local vs. distant CSR activity would be reduced if consumers have a strong sense of global identity. Because of the implicit nature of this egocentric bias, this behavioral effect should occur independently of explicit responses to the CSR activity (perceptions of importance) and to the company (attitude toward the company; company approval).

\subsection{Methodology}

The study relied on a between-subjects experiment where the geographic focus of the CSR activity was manipulated to be local or distant. Consumers' sense of global identity was measured to assess its moderating effect on the geographic focus.

A series of measures were collected 3 months before the study as part of a battery of questions administered to all subject pool participants at the beginning of the semester at a large public university in California. That preliminary survey included the measures of identification with being American $(\alpha=0.87)$ and global citizen identity $(\alpha=0.88)$. In the main study, conducted 3 months later, 75 members of the subject pool participated in an online experimental study for course credit. The study was self-paced and divided into separate phases so that respondents could not go back and change any previously given answers.

Participants were randomly assigned to two conditions. They were either exposed to a faux news article relating to a retailer's (J.Crew) actions in their country (the USA) or in another country (Cambodia). The statements were worded as not to mention a specific environmental issue or business operation. They read: "The Associated Press recently released a business news brief that clothing retailer J.Crew has pledged to institute a series of new programs to promote sustainable business practices for its US (Cambodian) operations. The company's director released a statement indicating the company was committed to protecting the environment in 
the US (Cambodia), especially given that many of its operations rely on area resources. The first of the new programs is scheduled to begin next month."

A series of explicit responses to the scenario was collected following the scenario: attitude toward the company $(\alpha=0.80)$, approval of the company's action $(\alpha=0.87)$, and perceived importance of the issue $(\alpha=0.88)$. Personal impact of the issue $(\alpha=$ 0.85 ) was also measured to serve as a check of the geographic focus manipulation. The order of these items was randomized. The Appendix contains the specific items for each measure.

The behavioral dependent measure was collected later in the study session. In a distracter study focused on brands and personality measures, participants were asked to indicate their future purchase intent of 14 listed brands, one of which was J.Crew, on a five-item scale anchored by 1 (not at all likely) and 5 (very likely). Participants were later asked to indicate how often they shop at each of the three retailers $(1=$ never $-5=$ frequently). The order of the brands was randomized in all instances to prevent order effects. Finally, standard demographic data were collected, including whether or not the respondent was a native of the USA. A complete debriefing was provided to all participants, including a description of J.Crew's actual CSR activities.

\subsection{Findings}

All non-US natives $(N=9)$ were removed from the analyses. The dependent variables were analyzed using multiple regression analysis. In a first step, the main effect of the geographic focus variable (local vs. distant) and global identity were included, and in the second step, their interaction was added to the model. Previous experience of the retailer, identity as an American, age, and gender were included in the analyses as covariates. For illustration of the findings, global identity was dichotomized (median= 3.40) and the means are reported and compared across weak and strong levels.

Only the main effect of focus is significant on personal impact $(t=2.18, p<0.05)$, demonstrating that the focus manipulation successfully created stronger perceptions of relevance in the home country scenario than in the distant scenario (2.58 vs. 2.04; contrast $=-0.54, p<0.05)$. Neither global identity nor its interaction with the focus manipulation is significant (both $t \mathrm{~s}<0.65, p>0.05$ ).

The regression of purchase intentions (PIs) reveals a main effect of geographic focus qualified by a significant geographic focus $\mathrm{X}$ global citizenship interaction but no main effect of global citizenship. The results appear in Table 1 and are visually depicted in Fig. 1. As predicted, for those with a weak global citizen identity, PIs are greater in the local than in the distant condition, thus reflecting an egocentric tendency, but among those with a strong identity as a global citizen, there are no differences in PIs.

Analyses of the other response variables reveal other significant differences. The regression of perceptions of issue importance reveals a main effect of geographic focus $(t=-3.16, p<0.05)$ and no effect of global identity or interaction (both $t \mathrm{~s}<1.35$, $p>0.05)$. However, the pattern is in the opposite direction to the PIs: the issue is perceived as more important in the distant country than in the home country (4.07 vs. 3.41 , contrast $=0.68, p<0.05)$. Both main effects are significant with regards to approval of the company. The effect of the CSR activity's geographic focus $(t=-1.96$, $p=0.05)$ is such that, in the distant country, approval is greater than in the home country ( 4.11 vs. 3.73 , contrast $=0.44, p<0.05)$ and the effect of consumers' global 
Table 1 Regression results

\begin{tabular}{|c|c|c|c|}
\hline Variable & Beta (SE) & $t$ or Wald & $\operatorname{Exp}(B)$ \\
\hline Study 1: multiple regression & DV: PI & & \\
\hline Focus: home vs. distant & $1.43(0.63)$ & $2.26^{*}$ & \\
\hline Global citizenship & $0.16(0.13)$ & $1.18 *$ & \\
\hline Focus X global citizenship & $-0.35(0.18)$ & $-1.95 *$ & \\
\hline Identity as American & $0.16(0.13)$ & 1.58 & \\
\hline Previous experience & $0.32(0.09)$ & $3.56^{*}$ & \\
\hline Constant & -0.53 & $2.18 *$ & \\
\hline Study 2: logistic regression & DV: choice & & \\
\hline Focus: home vs. distant & $6.26(3.20)$ & $3.83 *$ & 522.41 \\
\hline Environmental consciousness & $-2.93(1.05)$ & $7.71 *$ & 0.05 \\
\hline Focus $\mathrm{X}$ environmental consciousness & $-2.73(1.19)$ & $5.21 *$ & 15.27 \\
\hline Identity as Californian & $0.42(0.61)$ & 0.48 & 1.53 \\
\hline Identity as American & $-1.97(0.72)$ & $7.50^{*}$ & 0.14 \\
\hline Previous experience & $0.51(0.40)$ & 1.57 & 1.66 \\
\hline Constant & $5.92(4.01)$ & 2.18 & 372.88 \\
\hline Study 3: logistic regression & DV: choice & & \\
\hline Focus: local vs. distant & $-1.78(2.56)$ & 0.48 & 0.17 \\
\hline Primed identity (sub- or superordinate) & $-0.50(1.84)$ & 0.07 & 0.60 \\
\hline Level of identity & $-0.27(0.42)$ & 0.41 & 0.76 \\
\hline Focus $\mathrm{X}$ primed identity & $6.09(3.64)$ & 2.80 & 443.02 \\
\hline Focus X level of identity & $0.62(0.70)$ & 0.78 & 1.86 \\
\hline Primed identity X level of identity & $0.33(0.53)$ & 0.38 & 1.39 \\
\hline Focus $\mathrm{X}$ primed identity $\mathrm{X}$ level of identity & $-2.05(1.01)$ & $4.12 *$ & 0.13 \\
\hline Constant & $-0.30(1.41)$ & 0.045 & 0.74 \\
\hline
\end{tabular}

Age and gender were also included as covariates in all regressions $* p<0.05$

identity is such that company approval increases with consumers' global identity $(t=2.46, p<0.05)$. There were no effects on attitude toward the company.

\section{Discussion}

In line with the extant egocentrism literature, this first experiment shows that a CSR activity focused in a home country increases consumers' stated intentions to patronize the company in the future compared to a CSR activity focused in a foreign country. This effect occurs in the absence of explicit positive responses, such as more positive attitudes toward the company or greater approval. This pattern is in line with the egocentrism research and the principle of reciprocity: if consumers perceive that a company is doing something beneficial to them, they reward them with greater patronage. However, as anticipated, this egocentric tendency is reduced when consumers have a strong superordinate identity as a global citizen. The 
Fig. 1 PIs in study 1

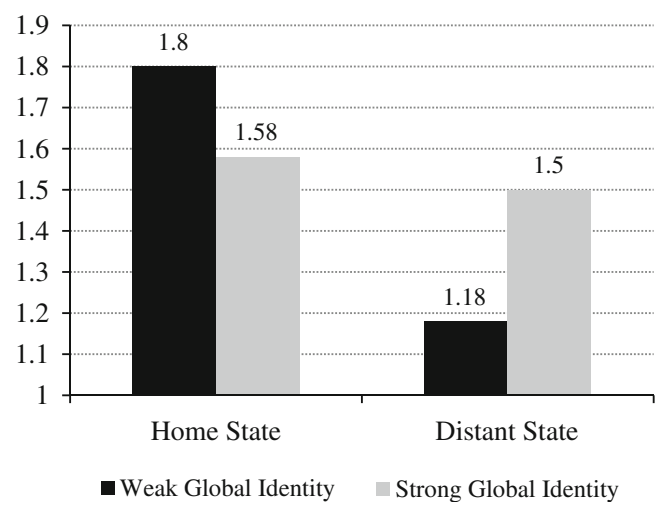

implicit nature of the egocentric response is evidenced by the opposite pattern of company approval and perceptions of importance. Indeed, despite this overall egocentric bias, consumers find the issue more important and approve of the company's actions more when the focus of their CSR activities is a foreign country. The findings suggest that, unless consumers have a strong identity as global citizens, reciprocity in the form of increased patronage emerges only when CSR activities are conducted locally, even though consumers may express explicit approval of geographically distant CSR activities.

\subsection{Limitations}

Study 1 is limited in that the main DV is a PI measure. Actual choice would be a stronger behavioral indicator of reciprocity. The use of countries is also a limitation, even though identity as an American was not significant in any of the analyses (perhaps because the mean in the sample was relatively high-4.12). Therefore, study 2 was conducted to reflect local vs. distant conditions that were within the same country and to measure actual choice.

\section{Study 2}

Expanding on the first study, study 2 compares consumers' actual patronage of a company following information regarding CSR activities conducted in their home state to those conducted in a distant state.

\subsection{Hypotheses}

As in the first study, a CSR activity focused locally is expected to generate reciprocity in the form of greater actual patronage of the company responsible for the CSR activity even though it may not increase company approval or attitudes toward the company. However, the effect on choice is expected to be moderated by a consumer's level of environmental consciousness such that egocentric tendencies would be reduced if consumers are highly concerned about the environment. 


\subsection{Methodology}

In this between-subjects experiment, the geographic focus of the CSR activity was manipulated to be local or distant, albeit within the same country. Consumers' environmental consciousness was measured.

Participants were students at a large public university in California who participated for course credit. As in study 1, a series of measures were collected before the study as part of a battery of questions administered to all subject pool participants. Specifically, the preliminary survey included the measures of environmental consciousness $(\alpha=0.72)$, identity as an American $(\alpha=0.87)$, and identity as a Californian $(\alpha=0.87)$.

Fifty-eight participated in an online experimental study, conducted 2 months later. The procedures and measures were the same as in the first study. In addition to receiving course credit, participants were entered in a lottery for a gift certificate for a retailer of their choice. This actual choice measure was collected at the conclusion of the experiment session and after a 15-min distracter study. Participants were asked to choose a gift certificate from one of three similar retailers: J.Crew, Banana Republic, and Abercrombie \& Fitch.

Participants were randomly assigned to two conditions with scenarios similar to those of study 1, except that the geographic focus was a US state. In the local condition, the news article related the retailer's actions in the local state, California. In the distant condition, the focus was a distant state, Maine, selected because it is at the opposite corner of the US from California. A complete debriefing was provided to all participants, including a description of J.Crew's actual CSR activities.

\subsection{Findings}

The results were the same whether or not non-California natives were included, so, because all participants currently lived in California, they were retained in the analyses. Actual brand choice was analyzed using a logistic regression with choice of J.Crew as the retailer for the gift certificate as a dependent variable (0/1). To test the hypotheses, choice was regressed on geographic focus, environmental consciousness, and their interactions. Identity as a Californian, identity as an American, previous shopping experience, and age and gender were included in the model. The results, presented in Table 1, indicate that the home scenario increased participants' selection of the retailer for their own gift certificate, reflecting the anticipated egocentric bias. However, this main effect is qualified by an interaction with environmental consciousness, such that the home scenario-induced choice is reduced as environmental consciousness increases. This moderating effect of environmental consciousness on the egocentric bias is similar to that found with global citizenship in study 1, except that, this time, it is emerging in an actual choice situation. The pattern of choice is presented visually in Fig. 2, with environmental consciousness dichotomized using a median split (median $=3.33$ ) on the pre-measures.

The other response variables were analyzed using multiple regressions on the same set of independent variables. There were no differences in company approval or attitude toward the company. As in study 1, the issue is perceived as more important in the distant scenario than in the home scenario, as revealed by a main 
Fig. 2 Choice in study 2

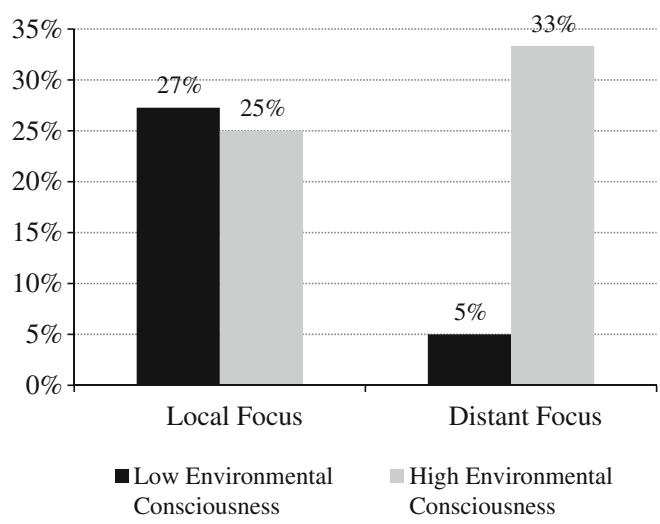

effect of geographic focus $(t=1.97, p=0.05)$ on issue importance (no other effects are significant).

\section{Discussion}

The pattern of brand choices is similar to that found in study 1. Again, as expected based on the egocentrism literature, a CSR activity focused locally, in one's home state, increases consumers' actual behavior toward the company compared to a CSR activity focused in a distant state. However, as anticipated, this egocentric tendency is reduced when consumers have a strong sense of environmental consciousness. This study also replicates the finding from study 1 that a distant CSR activity is perceived as more important, even though, in the end, consumers' actual choices still reflect an egocentric bias when it comes to their purchasing behaviors.

\section{Study 3}

Study 3 builds upon the findings of the first two studies. Instead of measuring the level of consumers' superordinate identities, this final study manipulates the salience of membership to a narrow group or a broad group to assess whether egocentric behaviors are a function of how one's in-group is defined. Identity-based theories predict that, when a superordinate identity is salient, people are more likely to take into account whether something benefits the broader group rather than their own subgroup (Kramer and Brewer 1984; Transue 2007). Priming a subordinate or superordinate identity changes the perceived boundary of the in-group (Gaertner et al. 1989); this has implications in terms of egocentric behavior because what is perceived as beneficial to oneself will vary according to the community most salient to the self. In turn, the impact on egocentric behaviors will vary according to the importance of that community in the person's identity. Egocentric behaviors emerge when a company's actions are perceived as benefiting one's in-group (Diekmann 1997) and should, therefore, occur when that group is salient and that group is an 
important part of one's identity. This interactive effect of identity prime and identity strength should occur whether one's in-group is narrowly or broadly defined (Transue 2007).

To ensure that the pattern of results in the first two studies is not context-specific, the final study focuses on a restaurant chain and its commitment to university scholarships. The geographic frame is also different, comparing CSR activities in one's home city vs. a distant city.

\subsection{Hypotheses}

Identity-based theories predict that, when a particular group identity is salient and strong, people will reward (by reciprocating) efforts that benefit their group, and therefore, themselves. Thus, a local CSR activity should trigger greater reciprocity, in the form of increased patronage of the company responsible for the CSR activity, from consumers who exhibit a strong sense of affiliation with that in-group and that in-group is primed. Similarly, when identity is high, a distant CSR activity should trigger greater reciprocity from consumers who strongly identify with the broad group and that group is primed. However, when levels of group identity (narrow or broad) are low, the basic reciprocation to the local activity should emerge, driven by egocentric tendencies, but priming a superordinate identity is expected to moderate this relationship such that reciprocation for the locally based CSR activity is reduced if membership to the broader community is salient. Therefore, egocentric tendencies to reciprocate toward a company should be a function not just of whether the CSR activity is local or distant, but also whether consumers are primed to and strongly do think of themselves as members of the narrow or broad community.

\subsection{Methodology}

This study relied on a $2 \times 2$ between-subjects experiment where the geographic focus of the CSR activity was manipulated to be local (home city) or distant (city across the country) and the salience of consumers' identity as university students was manipulated to reflect a narrow or broad group (their own or the whole US university community). As in previous research (Chong et al. 2001; Transue 2007), identity salience was manipulated by measuring, and therefore priming, identification with either a subgroup identity or a superordinate identity at the onset of the study.

One hundred and forty eight students at a large public university in California (58.8\% males) participated in the study for course credit. They were randomly assigned to one of the four experimental conditions. Participants first completed a six-item identity scale measuring the degree to which they felt a member of their own university community in the subordinate identity salience condition (e.g., "I feel good about being a college student at name of university"; $\alpha=0.90$ ) or of the broader US university community in the superordinate identity salience condition (e.g., "I feel good about being a college student in the US"; $\alpha=0.88$ ).

The participants were then exposed to a faux news article relating to a restaurant chain's (Panda Express) actions either in their city or in a city across the country. 
The statements read: "The Associated Press recently issued a business news brief that restaurant chain Panda Express has pledged to partner with universities to help offset student expenses. In addition to the high costs associated with attending college, New York (or home city in CA) is an expensive area to live and the company has pledged to sponsor multiple scholarships. The scholarship project is first being implemented in New York (or home city) next semester. The company's regional director released a statement indicating that Panda Express is committed to helping New York (or home city) students' during these difficult economic times."

Measures of attitude toward the company $(\alpha=0.75)$, approval of the company's action $(\alpha=0.86)$, and perceived importance of the issue $(\alpha=0.75)$ were collected after the scenario, as in the previous studies. A three-item measure of personal appreciation was also included (see the Appendix; $\alpha=0.89$ ). The order of all scale items was randomized.

In addition to receiving course credit, participants were entered in a lottery for a gift certificate for a restaurant of their choice. This actual choice measure was collected at the conclusion of the experiment session and after a 15-min distracter study. Participants were asked to choose from one of three restaurants that all had locations on the local campus (Panda Express, Rubio's, and Sub Connection) and to then justify their selection. These open-ended answers were coded to assess whether the company's CSR activities were mentioned (i.e., whether the choice was driven by a conscious decision to reward the company). All participants received a complete debriefing including a description of Panda Express' actual CSR activities.

\subsection{Findings}

Actual brand choice was analyzed using a logistic regression with choice of Panda Express for the gift certificate as a dependent variable (0/1). To test the hypotheses, choice was regressed on geographic focus, identity salience (subordinate vs. superordinate), level of identity (mean on the six-item scales), and the two- and three-way interactions. Age and gender were also included in the model. The results, presented in Table 1, reveal a significant three-way interaction, illustrated visually in Fig. 3, where the level of identity is dichotomized using a median split (median= 3.51; the median was the same for both identity with the broad community and identity with the narrow community). As expected, the choice of Panda Express is a function, not only of the geographic focus of its CSR activity, but also of the salience of group membership and the strength of consumers' identity as part of that group. When consumers feel strongly about a primed group identity, they reward the company for CSR efforts benefiting that group: priming a subordinate identity leads to greater reciprocation for the local CSR activity (42\%) and priming a superordinate identity greater reciprocation for a distant activity (45\%). The local CSR activity increases participants' selection of the restaurant if their subordinate identity is primed $(43.9 \%)$, and regardless of the degree to which they identify with the subordinate community, reflecting the baseline egocentric bias. When the superordinate identity is primed but participants report low levels of identification with that community, choice is lower (30\%). 


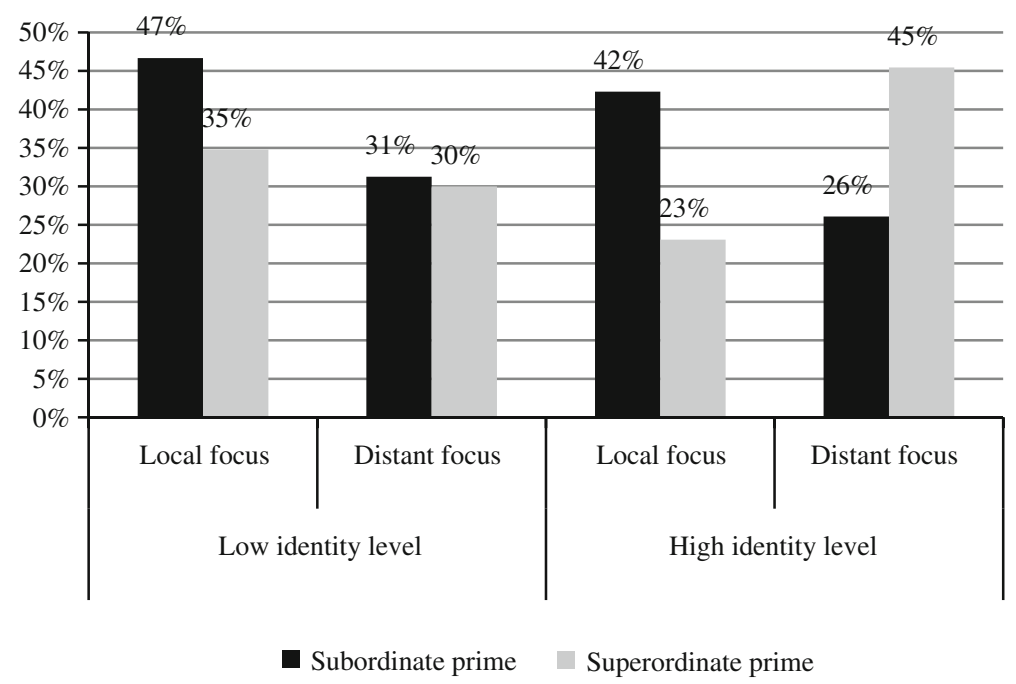

Fig. 3 Choice in study 3

Only two participants mentioned the preceding study in their restaurant selection, thus indicating that explicit concerns for reciprocation do not drive choices. The other response variables were analyzed using multiple regressions on the same set of independent variables and interactions amongst them. The only significant effect on personal appreciation and company approval is that of geographic focus $(t=2.15$ and 1.99 , respectively, $p<0.05)$ : the distant CSR activity generates greater expressions of personal appreciation (3.72 vs. 3.44) and company approval (4.26 vs. 4.03), again echoing the previous studies' findings that, explicitly, consumers respond even more positively to distant activities. There were no differences in attitude toward the company or perceived importance of the issue, both responses being positive across all conditions $(M=3.94, \mathrm{SD}=0.71 ; M=3.99, \mathrm{SD}=0.76)$.

\section{Discussion}

This third study, where different levels of group identity are primed, provides additional evidence for the egocentric bias and its implicit nature. The study also provides further evidence that explicit responses to a CSR activity operate independently from actual reciprocal behavior toward the company sponsoring it. In general, a local CSR activity increases reciprocal behavior if consumers' identity as members of the local community is salient. Also, when consumers do not strongly identify with a group, whether defined narrowly or broadly, the baseline pattern is a reciprocal behavior in reaction to a local CSR activity. Both patterns reflect an egocentric tendency. When a superordinate identity is salient and consumers strongly identify with it, consumers reciprocate more strongly when the CSR activity is conducted distantly because that distant location is viewed as part of their in-group. This pattern is also reflective of an egocentric bias because the action still benefits one's in-group, defined broadly, at a superordinate level. 


\section{Conclusion}

In discussing humans' egocentric tendencies, it has been argued that a truly intelligent person will overcome egocentric behaviors and act in a manner favorable to all human society, regardless of geographic location; however, this perspective comes with the caveat that "no man will ever be so intelligent as to see the needs of others as vividly as he recognizes his own" (Niebuhr 1932, p. 28). The three experiments conducted for this research indicate that, in general, consumers indeed exhibit egocentric behaviors: they increase their patronage of a company if, through its CSR activities, it does something directly beneficial to their in-group.

Egocentric behaviors emerge when a company's actions benefit one's in-group (Diekmann 1997) and when that group is salient and an important part of one's identity. At a baseline level, benefit to one's group is anchored on whether an activity is conducted locally. But if a superordinate identity is strong and salient in people's minds, the in-group can be defined more broadly. Indeed, in all experiments, the tendency to reciprocate more strongly to the local activity is moderated by consumers' superordinate identities: their sense of global identity in study 1, their environmental consciousness in study 2 , and the salience and magnitude of their feelings of membership to a broader community in study 3 . The general pattern of findings in this research is in line with the extant research on egocentrism and on social identity and the different ways in-groups are defined (Gaertner et al. 1989; Kramer and Brewer 1984).

An important characteristic of the egocentric bias is its implicit nature. Consumers do not explicitly state that their behaviors are driven by self-concern. In fact, the pattern for consumers' approval of a company is opposite that of actual patronage. In other words, consumers may state that they approve of what a company is doing elsewhere but this does not necessarily increase their purchasing of the company's products. Instead, reciprocal behavior is triggered by whether the company's activities are beneficial to oneself or one's own group. This implies that if a company's CSR efforts are not locally focused, then any attempt at promoting these efforts should emphasize a superordinate identity.

\section{Appendix}

Personal impact (1-strongly disagree and 5-strongly agree):

This pledge affects me directly.

This effort will have direct consequences for me.

This pledge is relevant to me.

Attitude toward the company (five-point semantic differentials):

I dislike it-I like it

It is a bad company-it is a good company

It is an irresponsible company-it is a responsible company

CSR action approval (1-strongly disagree and 5-strongly agree):

I approve of what (company) is doing.

I think (company)'s actions are worthwhile.

It is good that (company) takes responsibility and sets high standards for itself. 
CSR issue importance (1-strongly disagree and 5-strongly agree):

I believe that this is an important issue.

I think it is vital to tackle these issues.

I believe that businesses have a responsibility to address these issues.

Personal appreciation (1-strongly disagree and 5-strongly agree):

I am appreciative of what (company) is doing.

I am grateful for (company)'s efforts.

I am personally thankful for (company)'s initiative.

Open Access This article is distributed under the terms of the Creative Commons Attribution Noncommercial License which permits any noncommercial use, distribution, and reproduction in any medium, provided the original author(s) and source are credited.

\section{References}

Berger, I. E., \& Kanetkar, V. (1995). Increasing environmental sensitivity via workplace experiences. Journal of Public Policy \& Marketing, 14(2), 205-215.

Berman, S. L., Wicks, A. C., Kotha, S., \& Jones, T. M. (1999). Does stakeholder orientation matter? The Relationship between stakeholder management models and firm financial performance. Academy of Management Journal, 42(5), 488-506.

Cameron, J. (2004). A three-component model of social identification. Self and Identity, 3, 239-262.

Chong, D., Citrin, J., \& Conley, P. (2001). When self-interest matters. Political Psychology, 22(3), 541570.

Colonomos, A., \& Santiso, J. (2005). Vive la France! French multinationals and human rights. Human Rights Quarterly, 27(4), 1307-1345.

Daviss, B. (1999). Profits from principle: five forces redefining business. The Futurist, 33(3), $28-33$.

Dawkins, J., \& Lewis, S. (2003). CSR in stakeholder expectations: and their implication for company strategy. Journal of Business Ethics, 44(2/3), 185-193.

Dickinson, R., \& Hollander, S. C. (1991). Consumer votes. Journal of Business Research, 23(1), 9-20.

Diekmann, K. A. (1997). Implicit justifications and self-serving group allocations. Journal of Organizational Behavior, 18(1), 3-16.

Economist (2008). Just good business: A special report on corporate social responsibility. The Economist, 19 January, 1-22.

EIU. (2008). Doing good: Business and the sustainability challenge. London: Economist Intelligence Unit.

Ellemers, N., Kortekaas, P., \& Ouwerkerk, J. W. (1999). Self-categorisation, commitment to the group and group self-esteem as related but distinct aspects of social identity. European Journal of Social Psychology, 29, 371-389.

Falk, R. (1994). The making of global citizenship. In B. van Steenbergen (Ed.), The condition of citizenship (pp. 127-139). London: Sage.

Forehand, M., Deshpandé, R., \& Reed, A. (2002). Identity salience and the influence of differential activation of the social self-schema on advertising response. Journal of Applied Psychology, 87(6), 1086-1099.

Fornell, C., \& Larcker, D. (1981). Structural equation models with unobservable variables and measurement error. Journal of Marketing Research, 18(1), 39-50.

Gaertner, S. L., Mann, J., Murrell, A., \& Dovidio, J. F. (1989). Reducing intergroup bias: the benefits of recategorization. Journal of Personality and Social Psychology, 57(2), 239-249.

Gilovich, T., Medvec, V. H., \& Savitsky, K. (2000). The spotlight effect in social judgement: an egocentric bias in estimates of the salience of one's own actions and appearance. Journal of Personality and Social Psychology, 78(2), 211-222.

Handleman, J. M., \& Bello, R. (2004). Community oriented corporate social responsibility: consumer evaluation of community attachment. Advances in Consumer Research, 31, 314-315.

Harrison, J. S., \& Freeman, E. R. (1999). Stakeholders, social responsibility, and performance: empirical evidence and theoretical perspectives. Academy of Management Journal, 42(5), 479-485. 
Jetten, J., Postmes, T., \& McAuliffe, B. J. (2002). We're all individuals': group norms of individualism and collectivism, levels of identification and identity threat. European Journal of Social Psychology, 32, 189-207.

Jackson, J. W. (2002). Intergroup attitudes as a function of different dimensions of group identification and perceived intergroup conflict. Self and Identity, 1, 11-33.

Kang, G. D., \& James, J. (2007). Revisiting the concept of a societal orientation: conceptualization and delineation. Journal of Business Ethics, 73(3), 301-318.

Klein, J. G., \& Dawar, N. (2007). Corporate social responsibility and consumers' attributions and brand evaluations in a product-harm crisis. International Journal of Research in Marketing, 21(3), 203-217.

Klein, J. G., Smith, C. N., \& John, A. (2004). Why we boycott: consumer motivations for boycott participation. Journal of Marketing, 68(3), 92-109.

Kramer, R. M., \& Brewer, M. B. (1984). Effects of group identity on resource use in a simulated commons dilemma. Journal of Personality \& Social Psychology, 46(5), 1044-1057.

Luhtanen, R., \& Crocker, J. (1992). A collective self-esteem scale: self-evaluation of one's social identity. Personality and Social Psychology Bulletin, 18, 302-318.

Mannion, G. (2003). Schopenhauer, religion and mortality: The humble path to ethics. Burlington: Ashgate.

Marin, L., Rutz, S., \& Rubio, A. (2009). The role of identity in the effects of corporate social responsibility on consumer behavior. Journal of Business Ethics, 84, 65-78.

Morales, A. C. (2005). Giving firms an "E" for effort: consumer responses to high-effort firms. Journal of Consumer Research, 31(4), 806-812.

Niebuhr, R. (1932). Moral man and immoral society. New York: Charles Scribner's Sons.

Parekh, B. C. (1974). Jeremy Bentham, ten critical essays: Ten critical essays. London: Routledge.

Pivato, S., Misani, N., \& Tencati, A. (2008). The impact of corporate social responsibility on consumer trust: the case of organic food. Business Ethics: A European Review, 17(1), 3-12.

Podnar, K., \& Golob, U. (2007). CSR expectations: the focus of corporate marketing. Corporate Communications: An International Journal, 12(4), 326-340.

Powell, B. (2006). In reply to sweatshops. Human Rights Quarterly, 28(4), 1031-1042.

Reed, A., Aquino, K., \& Levy, E. (2007). Moral identity and judgments of charitable behaviors. Journal of Marketing, 71(1), 178-193.

Schlegelmilch, B. B., \& Bohlen, G. M. (1996). The link between green purchasing decisions and measures of environmental consciousness. European Journal of Marketing, 30(5), 35-55.

Sellers, R. M., Smith, M. A., Shelton, J. N., Rowley, S. A. J., \& Chavous, T. M. (1998). Multidimensional model of racial identity: a reconceptualization of African American racial identity. Personality and Social Psychology Review, 2(1), 18-39.

Tajfel, H., \& Turner, J. C. (1979). An integrative theory of intergroup conflicts. In W. G. Austin \& S. Worchel (Eds.), The social psychology of intergroup relations (pp. 33-47). Monterey: Brooks/Cole.

Transue, J. E. (2007). Identity salience, identity acceptance, and racial policy attitudes: American national identity as a uniting force. American Journal of Political Science, 51(1), 78-91.

Trudel, R. \& Cotte, J. (2008). Corporate reputation: Does being ethical pay? The Wall Street Journal, (12 May), R1.

Weigel, R. H., Hessing, D. J., \& Elffers, H. (1999). Egoism: concept, measurement and implications for deviance. Psychology, Crime \& Law, 5(4), 349-378.

Windsor, D. (2001). Corporate citizenship: Evolution and interpretation. In J. Andriof \& M. McIntosh (Eds.), Perspectives on corporate citizenship (pp. 39-52). Sheffield: Greenleaf. 